\title{
AZT exerts its antitumoral effect by telomeric and non-telomeric effects in a mammary adenocarcinoma model
}

\author{
ROMINA G. ARMANDO, DIEGO MENGUAL GOMEZ and DANIEL E. GOMEZ \\ Laboratory of Molecular Oncology, Department of Science and Technology, Quilmes National University, \\ Bernal 1876, Buenos Aires, Argentina
}

Received April 6, 2016; Accepted July 29, 2016

DOI: 10.3892/or.2016.5094

\begin{abstract}
Limitless replicative potential is one of the hallmarks of cancer that is mainly due to the activity of telomerase. This holoenzyme maintains telomere length, adding TTAGGG repetitions at the end of chromosomes in each cell division. In addition to this function, there are extratelomeric roles of telomerase that are involved in cancer promoting events. It has been demonstrated that TERT, the catalytic component of telomerase, acts as a transcriptional modulator in many signaling pathways. Taking into account this evidence and our experience on the study of azidothymidine (AZT) as an inhibitor of telomerase activity, the present study analyzes the effect of AZT on some telomeric and extratelomeric activities. To carry out the present study, we evaluated the transcription of genes that are modulated by the $\mathrm{Wnt} / \beta$-catenin pathway, such as c-Myc and cyclin-D1 (Cyc-D1) and cell processes related with their expression, such as, proliferation, modifications of the actin cytoskeleton, cell migration and cell cycle in a mammary carcinoma cell line (F3II). Results obtained after treatment with AZT $(600 \mu \mathrm{M})$ for 15 passages confirmed the inhibitory effect on telomerase. Regarding extratelomeric activities, our results showed a decrease of 64,38 and $25 \%$ in the transcription of c-Myc, Cyc-D1 and TERT, respectively $(\mathrm{p}<0.05)$ after AZT treatment. Furthermore, we found an effect on cell migration, reaching an inhibition of $48 \%(\mathrm{p}<0.05)$ and a significant passage-dependent increase on cell doubling time during treatment. Finally, we evaluated the effect on cell cycle, obtaining a decline in $\mathrm{G}_{0} / \mathrm{G}_{1}$ in AZT-treated cells. These results allow us to postulate that $\mathrm{AZT}$ is not only an inhibitor of telomerase activity, but also a potential modulator of extratelomeric processes involved in cancer promotion.
\end{abstract}

Correspondence to: Dr Daniel E. Gomez, Laboratory of Molecular Oncology, Department of Science and Technology, Quilmes National University, R. Sáenz Peña 352, Bernal 1876, Buenos Aires, Argentina

E-mail: degomez@unq.edu.ar

Key words: AZT, c-Myc, Cyc-D, telomerase, TERT, cancer

\section{Introduction}

Most tumor cells have an unlimited replicative potential, mainly due to the presence of the active telomerase holoenzyme, showing it as an attractive target for cancer therapies. Telomerase is a ribonucleoprotein complex that adds telomeric sequences at the end of the chromosome, maintaining telomere length in tumor cells (1). The human holoenzyme telomerase is a ribonucleoprotein composed by a catalytic subunit, (hTERT) and an RNA component (hTR) which acts as a template for the addition of a short repetitive sequence d(TTAGGG)n in the 3 ' end of the telomeric DNA and species-specific accessory proteins (2). Recently, it has been demonstrated that dyskerin binds to hTR, giving it the right conformation to ensemble with hTERT, being essential for the conformation of an active enzyme. Additionally N0P10, NHP2 and GAR1 proteins provide greater stability to the complex while pontin and reptin are two closed ATPases necessary for the stability of dyskerin and hTR in vivo (3).

3'-Azido-2',3'-dideoxythymidine [azidothymidine (AZT) or zidovudine] is a thymidine analogue used in the treatment of AIDS since it competitively inhibits reverse transcriptase (RT). The main component of telomerase, hTERT, is a catalytically active RT structurally similar to HIV-1 RT (4). Such similarity prompted studies on the feasibility of telomerase inhibition with a known inhibitor of viral RT such as AZT. In our laboratory, it was demonstrated for the first time that AZT is incorporated preferentially in the telomeric DNA of $\mathrm{CHO}$ cells (5). Few years later, we demonstrated the inhibitory action of AZT on telomere dynamics (6), and later we found that the cells of an experimental mammary carcinoma (F3II) treated for prolonged periods with no cytotoxic doses of AZT enter into senescence and programmed cell death (7).

Besides its role in telomere maintenance (canonical function), TERT has additional functions. They are related, with regulation of cell behavior, but in a telomeric-independent manner (noncanonical). For instance, TERT can function as a transcriptional modulator of the signaling pathway Wnt/ $\beta$-catenin $(8,9)$. In this manner, TERT acts as a cofactor in a transcriptional complex of $\beta$-catenin through interactions with a chromatin remodelling protein, allowing regulation of target genes of this pathway (10). Good examples are cyclin-D1 (Cyc-D1), which plays a key role in cell cycle progression (11) and c-Myc with a direct link to cell growth, differentiation and apoptosis (12). 
In order to increase insight into the mechanism of action of AZT as an anticancer drug, the present study analyzed the possible effects of AZT treatment on the transcription of genes involved in the signaling pathway Wnt/ $\beta$-catenin (TERT, cMyc and Cyc-D1) its effect on telomerase activity, cytoskeleton structure, tumor cell migration and cell cycle in a murine mammary adenocarcinoma cell model (F3II).

\section{Materials and methods}

Cell line and culture conditions. The mammary carcinoma cell line F3II is a highly aggressive and metastatic variant, established from a clonal subpopulation of a spontaneous hormone-independent BALB/c mouse mammary tumor (13). Cells were grown in Dulbecco's modified Eagle's medium (DMEM) (Life Technologies) supplemented with 10\% heat-inactivated fetal bovine serum (FBS), $2 \mathrm{mM}$ glutamine and $80 \mu \mathrm{g} / \mathrm{ml}$ gentamicin at $37^{\circ} \mathrm{C}$ in $5 \% \mathrm{CO}_{2}$ atmosphere. Cell cultures were routinely subculture by trypsinization using standard procedures.

Cell proliferation assay. Cells $\left(1 \times 10^{4}\right)$ were plated in 96-well plates, and then treated with different concentration of AZT (50-2,000 $\mu \mathrm{M}$ ) for $72 \mathrm{~h}$. Cell growth was measured by colorimetric MTT assay (Sigma). The concentration producing $50 \%$ inhibition $\left(\mathrm{IC}_{50}\right)$ was determined by non-linear regression function of GraphPad Prism $6^{\circledR}$. Results shown correspond to the average of three individual experiments. Furthermore, in order to demonstrate that AZT was not toxic at this dose, another control with AZT in parallel with the untreated control cells was added on the experiments on doubling time, telomerase activity and cell migration.

RNA extraction and cDNA synthesis. For each treatment, total RNA was isolated by extraction with TRIzol reagent (Life Technologies) according to the manufacturer's specifications. cDNA synthesis was performed using SuperScript III First-Strand Synthesis System (Life Technologies) from $\sim 1 \mu \mathrm{g}$ of total RNA with oligonucleotide dT18 (Life Technologies) according to the manufacturer's instructions. All cDNA samples were normalized by quantification at $260 \mathrm{~nm}$ in NanoDrop 1000 (Thermo).

Analysis of Cyc-D1, c-Myc and TERT transcription by real-time PCR. Specific primers were designed for each target using the Primer Express ${ }^{\circledR}$ Software Version 3.0 (Life Technologies). All primers designed presented efficiency values between 90 and 100\%, and suitable dynamic ranges, allowing its proper use. The assays were carried out on One-Step Real-Time PCR System (Life Technologies) using SYBR-Green detection reagent (Life Technologies). $\beta$-actin transcript was used as a loading control. Once optimized all the parameters for RT-qPCR, the analysis of transcriptional expression was carried out by the $\Delta \Delta \mathrm{Ct}$ method.

Determination of telomerase activity. Telomerase activity was determined by TRAP assay, using RT-qPCR method with SYBR-Green (StepOne ${ }^{\text {TM }}$ System equipment). The growing tumor cells were harvested and washed once with phosphatebuffered saline (PBS). Cells $\left(2 \times 10^{6}\right)$ were transferred to $1.5 \mathrm{ml}$ conical tubes and centrifuged for $8 \mathrm{~min}$ at $450 \mathrm{x} \mathrm{g}$. The pellet was lysed with $200 \mu \mathrm{l}$ of buffer CHAPS (RNaseOUT + Protease Inhibitor), quantified and stored at $-20^{\circ} \mathrm{C}$ until use.

Actin staining. Control and AZT-treated cells were grown in glass coverslips in serum-free DMEM. Cells were fixed in $4 \%$ formaldehyde in PBS and stained with Alexa Fluor 555-conjugated phalloidin (Molecular Probes, Life Technologies) following the manufacturer's instructions. Images were recorded by an inverted fluorescence microscope (Nikon Eclipse T2000). Alternatively, a quantitative analysis in which the intensity of emitted fluorescence of the same reagent was determined by measurement in a fluorometer Synergy HT (BioTek).

Cell migration. Cell migration was measured using an in vitro wound healing assay as previously described (14). Briefly, in vitro 'scratch' wounds were created by scraping confluent F3II (controls and 5, 10 and 15 AZT passages) monolayers with a sterile pipette tip. After $16 \mathrm{~h}$ incubation in DMEM with $10 \%$ FBS in the presence or absence of AZT, cells were fixed and stained. Ten random micrographs/well were obtained and migration area was quantified using NIS-Elements 3.0 (Nikon) software.

Cell cycle. For cell cycle analysis by flow cytometry, cells were washed and incubated in serum-free DMEM for synchronization for $24 \mathrm{~h}$. Cells, both control and treated with AZT $600 \mu \mathrm{M}$ for passages 5,10 and 15 were cultured, trypsinized and centrifuged at $450 \mathrm{x}$ g. Cells were fixed in $70 \%$ methanol in PBS and stained with propidium bromide $(1 \mathrm{mg} / \mathrm{ml})$ (Life Technologies). Cell cycle progression was analyzed in a BD FACSCalibur ${ }^{\mathrm{TM}}$ (BD Biosciences) flow cytometer. Before recording 10,000 events, the verification of the doublet discrimination function of the flow cytometer was performed using DNA QC Particles kit (BD Biosciences).

Doubling time assay. Cells $\left(1,5 \times 10^{4}\right)$ treated with AZT $600 \mu \mathrm{M}$ for 5, 10 and 15 passages were plated in 12-well plates. After incubation with DMEM 10\% FBS and AZT treatment for 24, 48, 72 and $96 \mathrm{~h}$, each plate was stained and fixed by $0.5 \%$ violet crystal $20 \%$ methanol, resuspended in $500 \mu \mathrm{l}$ of ethanol: acetic acid (3:1) and measured at $570 \mathrm{~nm}$. A growth curve was built, where the $100 \%$ was defined as the $24 \mathrm{~h}$ value for each condition.

Statistical analysis. All data are presented as the mean \pm SD. Significant differences were determined by one-way ANOVA with Dunnett contrast, and two-way ANOVA with a Bonferroni's multiple comparisons test. The analyses were performed by GraphPad Prism 6 software (GraphPad Software, La Jolla, CA, USA). The criterion for a statistical significance is $\mathrm{p}<0.05$.

\section{Results}

Effect of AZT on cell viability. In order to confirm the effect of AZT on cell viability, we determined the $\mathrm{IC}_{50}$ of this molecule for F3II cell line, obtaining a value of $1,195 \pm 37 \mu \mathrm{M}$. Regarding the data, we determined $600 \mu \mathrm{M}$ as the treatment dose, equivalent to an $\mathrm{IC}_{25}$ value. 
Telomerase activity

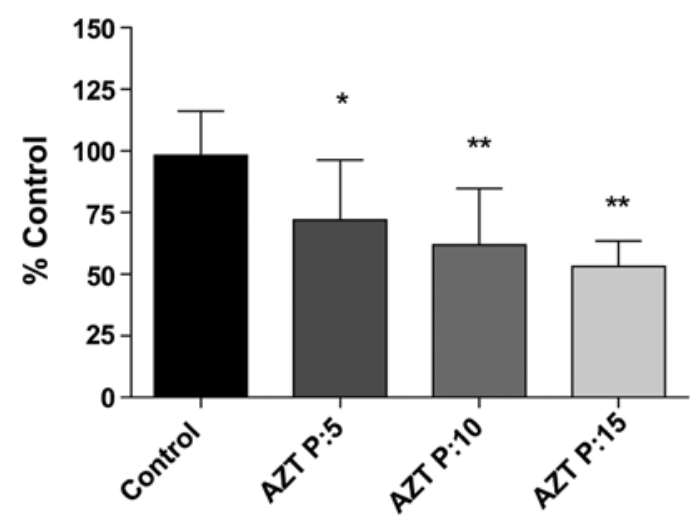

Figure 1. Determination of telomerase activity by qPCR. Quantification was performed by real-time PCR with specific primers using as template protein lysates obtained from the treated cells, at different passages $(\mathrm{P})$. Values represent mean $\pm \operatorname{SEM}\left(\mathrm{n}=6,{ }^{*} \mathrm{p}<0.05\right.$ and ${ }^{* *} \mathrm{p}<0.01$ vs. the control) (ANOVA with Dunnett contrasted).

Determination of telomerase activity. Telomerase activity significantly decreased and was evaluated progressively during the period. Telomerase activity dropped $26.22 \%(\mathrm{p}<0.05)$, $36.27 \%(\mathrm{p}<0.01)$ and $45.08 \%(\mathrm{p}<0.001)$ after 5, 10 and 15 passages with AZT, respectively (Fig. 1). In this manner, corroborating the inhibitory function of AZT on telomerase activity.

Analysis of TERT, $c-M y c$ and Cyc-Dl transcription. We quantified relative expression by $\Delta \Delta \mathrm{Ct}$ method of the expression of TERT, Cyc-D1 and c-Myc genes, where $\beta$-actin gene was used as endogenous loading control.

We determined the relative expression of TERT and confirmed its expression was influenced by the treatment, in a passage-dependent manner. After 5 passages TERT expression decreased by $17.1 \%(\mathrm{p}<0.05)$, at 10 passages, expression reduced by $20.28 \%(\mathrm{p}<0.05)$ and at the end of treatment had declined by $30.91 \%$ (p<0.05) (Fig. 2C).

Regarding the expression of Cyc-D1 in cells treated with AZT, we found a passage-dependent decrease. After 5, 10 and 15 passages, we observed a decline of $24.52 \%(\mathrm{p}<0.05)$, $30.87 \%(\mathrm{p}<0.05)$ and 38.24\% (p<0.01), respectively (Fig. 2A).

Analyzing c-Myc we found a more pronounced decline, reaching $34.14 \%(\mathrm{p}<0.01), 43.85 \%(\mathrm{p}<0.001)$ and $64.2 \%$ $(\mathrm{p}<0.01)$ of inhibition at 5,10 and 15 treated passages, respectively (Fig. 2B).

Anti-migratory effect of AZT. Due to the changes in the transcription of c-Myc, we expected an effect on cell migration. Using the wound assay, we analyzed this effect on cells treated with $600 \mu \mathrm{M}$ AZT for 5, 10 and 15 passages. After 5 passages significant effects on cell migration were not seen. However, after 10 and 15 passages, the invaded area decreased $31 \%$ $(\mathrm{p}<0.01)$ and $47.79 \%(\mathrm{p}<0.01)($ Fig. 3).

Evaluation of the actin cytoskeleton. Control cells showed normal actin fibers in most cells with intense fluorescence on the whole cell area (Fig. 4A). At passage 5 treated cells exhibited some fluorescence in the cell periphery and also actin fibers like the untreated ones (Fig. 4B). Changes in the cytoskeleton were evident after passage 10. Cells had less actin fibers whereas a greater amount of cortical fluorescence was observed (Fig. 4C). Similar effect was observed at passage 15, where the fluorescence was much more diffuse, actin fibers were no longer present, and low fluorescence intensity was observed in the cytoplasm (Fig. 4D).

Effect of AZT on growth and the cell cycle. Cell populations were without significant differences throughout all phases of the cell cycle (Fig. 5). There were slight differences in the cell proportions in each cell cycle stage, but along the treatment, cells growth rate was not the same between control and treated cells. Once discarded effects on cell cycle arrest, we proceeded to determine doubling times of cells during treatment with AZT. Doubling time determination was performed by cell counting after $24,48,72$ and $96 \mathrm{~h}$. The F3II cell line in normal growth presented a doubling time of $22.82 \mathrm{~h}$. At passage 5 after treatment, the doubling time was $43.13 \mathrm{~h}$, at 10 passages was $56.21 \mathrm{~h}$, and finally after 15 passages was 67.22 h (Fig. 6). This information demonstrates a clear and progressive increase in the doubling time, in relation with the number of passages treated with AZT.
Cyc-D1 mRNA levels

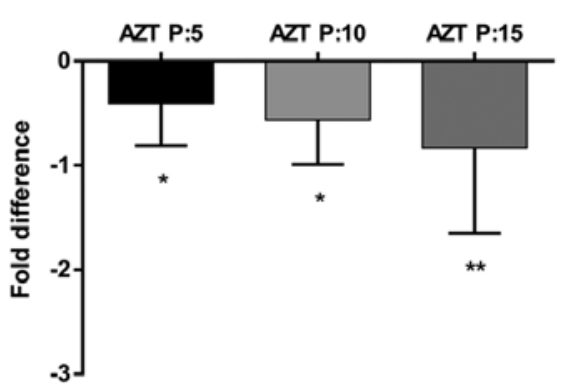

C-myc mRNA levels

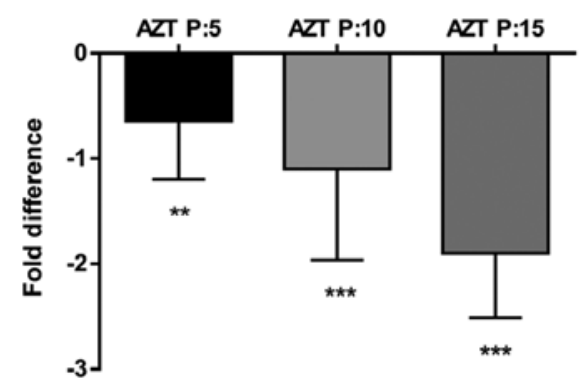

TERT mRNA levels

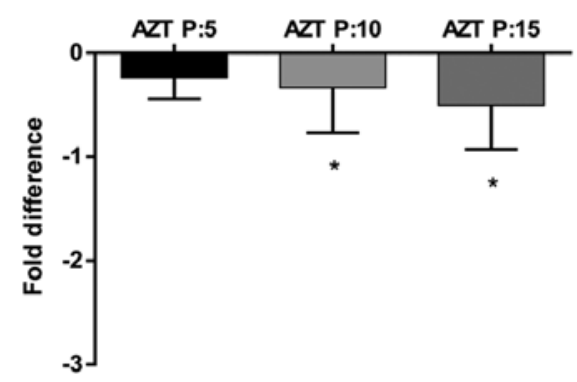

Figure 2. Determination of gene expression of Cyc-D1, c-Myc and TERT. Relative quantitation was performed by qPCR of the target genes using as charge control gene $\beta$-actin. Values represent mean \pm SEM ( $n=6$; ${ }^{*} p<0.05$ and ${ }^{* *} \mathrm{p}<0.01$ vs. the control) (ANOVA with Dunnett contrast). Asterisks are indication of significant difference in comparison with untreated cells (fold difference, 0 ). 
Migration

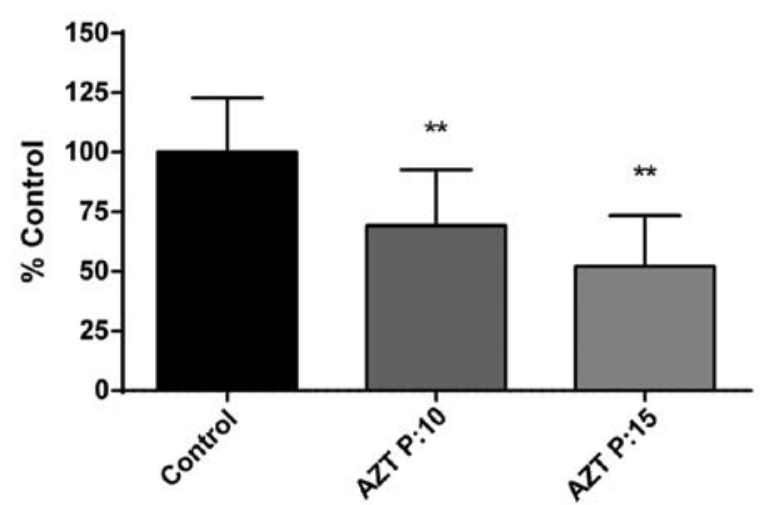

Control

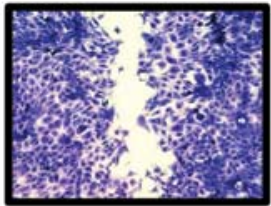

AZT P:10

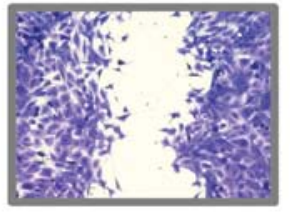

AZT P:15

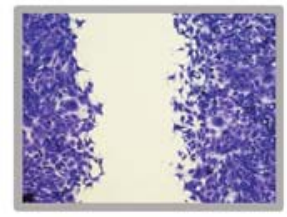

Figure 3. Evaluation of the effect of AZT on cell migration. Evaluated by scratch wound. Crystal violet staining, magnification x200. Quantification was performed using the NIS-Elements 3.0 software. Values represent mean $\pm \operatorname{SEM}\left(\mathrm{n}=6\right.$; ${ }^{*} \mathrm{p}<0.05$ and ${ }^{* *} \mathrm{p}<0.01 \mathrm{vs}$. the control) (ANOVA with Dunnett contrast).

\section{Control}

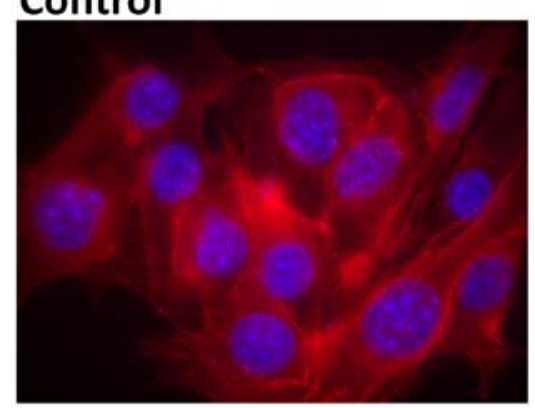

AZT P:10

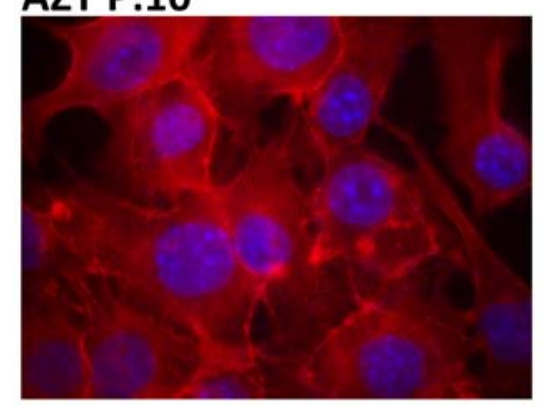

AZT P:5

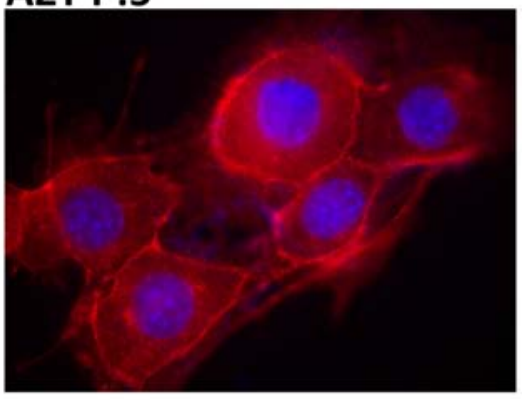

AZT P:15

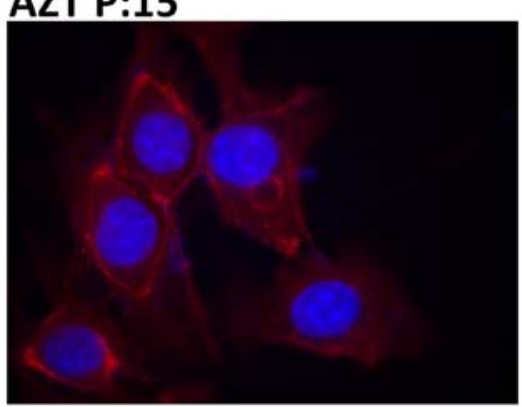

Figure 4. Evaluation of the effect of AZT on the cytoskeleton. Changes in the actin cytoskeleton (phalloidin and DAPI staining) was assessed by fluorescence microscopy. Magnification, x1,000.

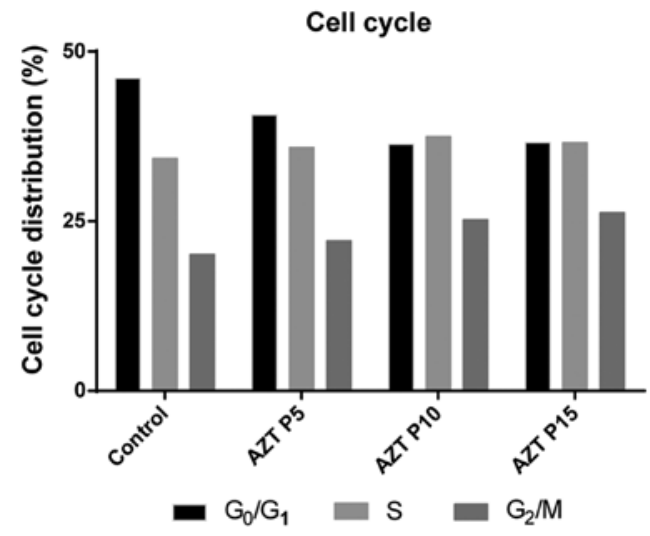

Figure 5. Effect of AZT on the cell cycle. The assay was performed by flow cytometry with propidium iodide staining (BD FACSCalibur). Events $(10,000) /$ sample were acquired.

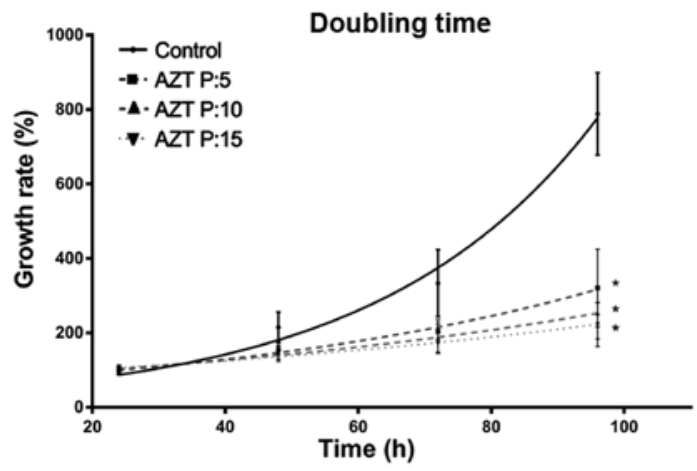

Figure 6. Analysis of AZT treatment on cell doubling time. Cells (15,000/well) were seeded in 12-wells. Plates with crystal violet and reading at $570 \mathrm{~nm}$ revealed every 24 for $96 \mathrm{~h}$. A growth curve given as $100 \%$ measured at $24 \mathrm{~h}$ for each treatment was built. Statistical analysis was performed by comparing the non-linear adjustment curves through its parameters. 


\section{Discussion}

3-Azido-2,3-dideoxythymidine [azidothymidine (AZT) or zidovudine] was the first reported telomerase inhibitor. The mechanism of AZT antitumor action still remains elusive. AZT is able to transform an immortal cell in a mortal one. It has been said that this was due to its action as a chain terminator. Although the experimental results support this view, AZT by itself could produce a specific antitumor action by other means, independently of its action as a telomerase inhibitor. Lately, a number of non-telomeric telomerase functions have been described. For instance, TERT, the main component of telomerase, allows the regulation of target genes of the signaling pathway Wnt/ $\beta$-catenin (15), highlighting Cyc-D1 and $\mathrm{C}$-myc. In the present study, we intend to demonstrate that canonical and non-canonical functions of telomerase are affected by AZT in the same cell line and with the same dose integrating the different mechanisms of action underlying the role of AZT in tumor biology (16).

Chronic treatment with a dose of $600 \mu \mathrm{M}$ of AZT progressively decreased the telomerase activity along 15 passages in F3II cell line without effects on cell viability. Our group was the first to find this effect using $800 \mu \mathrm{M}$ (6). Later, many other authors confirmed this finding. In the present study we found at $600 \mu \mathrm{M}$, that expression levels of TERT were significantly reduced through the passages evaluated. Given that, it has been reported that TERT acts as a modulator of $\beta$-catenin/BRG1 transcriptional complex, which acts on target genes of the signaling pathway Wnt/ $\beta$-catenin, it is evident to expect that a decrease in the expression levels of TERT negatively impacts on expression of C-Myc and Cyc-D1 genes. Our results revealed a continuing decline, corresponding with the amount of passages, in the expression of both genes, reaching expression levels up to two-fold reduction for C-Myc and onefold reduction to Cyc-D1. This result allows us to infer that the decline in TERT expression due to treatment with AZT, could be affecting its role as a positive regulator of these genes, coinciding with studies in the literature who analyze knockdown models of TERT (17). Ji et al demonstrated in 2005 that intermittent treatment with AZT initially suppressed hTERT and then c-Myc. Similar results were found by Jin et al in 2012 (18).

Regarding variations in Cyc-D1 after AZT treatment, we found a passage-dependent decrease reaching $38.24 \%$ at 15 passages. Downregulating expression of Cyc-D1 is a clear marker of changes or modulation in the cell cycle, being the protein which is required for $\mathrm{G}_{1} / \mathrm{S}$ cell cycle progress. The decrease of this factor represents a cycle arrest in phase $\mathrm{G}_{0} / \mathrm{G}_{1}$ cell cycle. Due to the evidence collected regarding the expression of Cyc-D1, cell cycle analysis was performed by flow cytometry. As a result of this assay, we determined there was no such arrest. Similarly, Datta et al showed that long-term AZT-treated MT-2 cells arrest in all phases of the cell cycle (19). Fang et al found that cyclin-A was increased at early times after AZT treatment cyclin-dependent kinase 1 was decreased at later time points, while it was found that AZT-treated compared to untreated mice downregulated Cyc-D2 ( $p=0.0003)(20)$. However, some authors have found different results in other models. Olivero et al found that AZT induced an upregulation of Cyc-D1 accompanied by a downregulation of the Cyc-D1-associated inhibitors P18 and P57 (21). Regarding the decline found in a Cyc-D1 expression after treatment, it is important to highlight the key role played by this protein in cell cycle entry. The first approximation of this effect was based on the impact it would have on this process expecting an increase in the proportion of cells in state $G_{0} / G_{1}(22)$. The results obtained on the cell cycle assay did not allow us to observe this phenomenon, showing a decrease in the proportion of cells in $\mathrm{G}_{1}$ phase; a constant proportion of cells in $S$ phase and an increased $\mathrm{G}_{2} / \mathrm{M}$ phase at the long-term AZT-treated cells. One possible interpretation for this observed phenomenon could be based on the fact that treatment with AZT increased levels of p21 mRNA (23). This protein is known for its role in controlling the cell cycle through inhibition of complex E/cdk2 and A/cdk2, being able to stop the progression of the cell cycle. In addition to this, during $\mathrm{S}$ phase, it is also able to inhibit CDK1-cyclin-A and CDK2-cyclin-A, which are required for progression through $\mathrm{S}$ and $\mathrm{G}_{2}$, respectively (24). Another possible alternative to this alteration of the cell cycle, which also involves p21, is the relationship between this protein and c-Myc, being the last one presented as a repressor of p21 expression. At lower levels of expression of c-Myc, p21 levels increase, leading the regulation of different cell cycle cyclins. These facts could explain the differences between the cell amount in each phases of the cell cycle observed after treatment (25).

In addition, has been reported that c-Myc has an important role in what concerns mitosis and DNA replication, being a regulator of the target genes Cdc6, Cdt1, MCM3, 4 and 5 and other genes associated with this processes (22). This explanation coincides with was observed in our results of doubling time performed on cells at different passages $(0,5,10$ and 15), where the average doubling time is increased significantly along passages, suggesting that the AZT could impact in mitosis and duplication of the treated cells.

Chronic treatment with AZT decreases cell migration, and substantially modifies the reorganization of actin cytoskeleton, finding passage-dependent response in a high aggressiveness model as F3II. The literature suggests that there is a link between the expression of c-Myc and invasive phenotype of the cell that correlates high expression of this gene with increased migratory ability (26). Our results agree with this evidence, observing that along the treatment the expression of this gene is diminished as well as migration and actin filament formation, indicating that the treated cells have an epithelial phenotype which it was associated with a less aggressive profile. This link between c-Myc, cytoskeleton and migration is described in literature and it was related to the effect of c-Myc on signaling via RhoA/ROCK, which is highly related to the regulation of epithelial-mesenchymal transition, motility cell signaling and cytoskeletal organization (27). Focussing on the results obtained, we can postulate that AZT treatment has an effect on cell migration, probably through the regulation of c-Myc and TERT by AZT, leading tumor cells to a less aggressive phenotype, being a remarkable event in the field of extratelomerics activities. To the best of our knowledge no previous study has focused on cell migration after AZT treatment.

In conclusion, the results and information presented here, are intended to clarify and contribute to the study of how 
AZT exerts its antitumoral effect. Telomerase stands at the crossroads of multiple signaling pathways and its upregulation/reactivation leads to the modulation of critical cellular processes, including gene expression and metabolism. Understanding AZT antitumoral action is of utmost importance, even more since the recent report of Bhushan and Kush on the pharmocophoric studies of anti-telomerase drugs. They found that AZT and few non-nucleoside HIV-RTIS have exquisite selectivity, not requiring bioactivation by kinases to triphosphate and not attaching into growing DNA chain. Instead, binding to allosteric site of the reverse transcriptase that is distinct from the substrate binding site. Therefore, they bind reverse transcriptase near catalytic site and instantly denature it by the non-competitive mechanism (28).

Although most of the described effects were known, this is the first time that the mentioned variables were analyzed after treatment with AZT using the same treatment, in the same cell line and at the same time, providing evidence that they are not interfering among them, and that AZT inhibitory action may be due to a mix of canonical and non-canonical effects.

Even knowing that more experiments are needed, we started a differential display study with cells treated or not with AZT. Preliminary results point toward the described dual effect.

\section{Acknowledgements}

The authors wish to express their gratitude to Dr Daniel Alonso for critical reading of the manuscript. The present study was supported by grants from UNQ and ANPCyT (Argentina). Daniel E. Gomez and Diego Mengual Gómez are members of the National Research Council (CONICET, Argentina).

\section{References}

1. Teralı K and Yilmazer A: New surprises from an old favourite: The emergence of telomerase as a key player in the regulation of cancer stemness. Biochimie 121: 170-178, 2016.

2. Martínez P and Blasco MA: Replicating through telomeres: A means to an end. Trends Biochem Sci 40: 504-515, 2015.

3. Gomez DE, Armando RG, Farina HG, Menna PL, Cerrudo CS, Ghiringhelli PD and Alonso DF: Telomere structure and telomerase in health and disease (Review). Int J Oncol 41: 1561-1569, 2012.

4. Hájek M, Matulová N, Votruba I, Holý A and Tloust'ová E: Inhibition of human telomerase by diphosphates of acyclic nucleoside phosphonates. Biochem Pharmacol 70: 894-900, 2005.

5. Gomez D, Kassim A and Olivero O: Preferential incorporation of 3'-azido-2',3'-dideoxythymidine (azt) in telomeric sequences of cho cells. Int J Oncol 7: 1057-1060, 1995.

6. Gomez DE, Tejera AM and Olivero OA: Irreversible telomere shortening by 3'-azido-2',3'-dideoxythymidine (AZT) treatment Biochem Biophys Res Commun 246: 107-110, 1998.

7. Tejera AM, Alonso DF, Gomez DE and Olivero OA: Chronic in vitro exposure to 3'-azido-2', 3'-dideoxythymidine induces senescence and apoptosis and reduces tumorigenicity of metastatic mouse mammary tumor cells. Breast Cancer Res Treat 65 93-99, 2001.

8. Koh CM, Khattar E, Leow SC, Liu CY, Muller J, Ang WX, Li Y, Franzoso G, Li S, Guccione E, et al: Telomerase regulates MYC-driven oncogenesis independent of its reverse transcriptase activity. J Clin Invest 125: 2109-2122, 2015.
9. Park JI, Venteicher AS, Hong JY, Choi J, Jun S, Shkreli M, Chang W, Meng Z, Cheung P, Ji H, et al: Telomerase modulates Wnt signalling by association with target gene chromatin. Nature 460: 66-72, 2009.

10. Martínez P and Blasco MA: Telomeric and extra-telomeric roles for telomerase and the telomere-binding proteins. Nat Rev Cancer 11: 161-176, 2011.

11. De Leonardis F, Monti L, Gualeni B, Tenni R, Forlino A and Rossi A: Altered signaling in the G1 phase deregulates chondrocyte growth in a mouse model with proteoglycan undersulfation. J Cell Biochem 115: 1779-1786, 2014.

12. Li Y, Casey SC and Felsher DW: Inactivation of MYC reverses tumorigenesis. J Intern Med 276: 52-60, 2014.

13. Alonso DF, Farías EF, Urtreger A, Ladeda V, Vidal MC and Bal De Kier Joffé E: Characterization of F3II, a sarcomatoid mammary carcinoma cell line originated from a clonal subpopulation of a mouse adenocarcinoma. J Surg Oncol 62: 288-297, 1996.

14. Segatori VI, Otero LL, Fernandez LE, Gomez DE, Alonso DF and Gabri MR: Antitumor protection by NGcGM3/VSSP vaccine against transfected B16 mouse melanoma cells overexpressing $N$-glycolylated gangliosides. In Vivo 26: 609-617, 2012.

15. Chen YY, Wu XQ, Tang WJ, Shi JB, Li J and Liu XH: Novel dihydropyrazole-chromen: Design and modulates hTERT inhibition proliferation of MGC-803. Eur J Med Chem 110: 65-75, 2016.

16. Gomez DE, Armando RG and Alonso DF: AZT as a telomerase inhibitor. Front Oncol 2: 113, 2012.

17. Ji HJ, Rha SY, Jeung HC, Yang SH, An SW and Chung HC: Cyclic induction of senescence with intermittent AZT treatment accelerates both apoptosis and telomere loss. Breast Cancer Res Treat 93: 227-236, 2005.

18. Jin RR, Chao R, Xi YM, Chen C, Chu HY, Li M and Zhang H: Effects of AZT on leukemia cell line KG-1a proliferation and telomerase activity. Zhongguo Shi Yan Xue Ye Xue Za Zhi 20: 277-281, 2012.

19. Datta A, Bellon M, Sinha-Datta U, Bazarbachi A, Lepelletier Y, Canioni D, Waldmann TA, Hermine O and Nicot C: Persistent inhibition of telomerase reprograms adult T-cell leukemia to p53-dependent senescence. Blood 108: 1021-1029, 2006

20. Fang JL, McGarrity LJ and Beland FA: Interference of cell cycle progression by zidovudine and lamivudine in NIH 3T3 cells. Mutagenesis 24: 133-141, 2009.

21. Olivero OA, Tejera AM, Fernandez JJ, Taylor BJ, Das S, Divi RL and Poirier MC: Zidovudine induces S-phase arrest and cell cycle gene expression changes in human cells. Mutagenesis 20: 139-146, 2005.

22. Bretones G, Delgado MD and León J: Myc and cell cycle control. Biochim Biophys Acta 1849: 506-516, 2015.

23. Hassani S, Ghaffari SH, Zaker F, Mirzaee R, Mardani H, Bashash D, Zekri A, Yousefi M, Zaghal A, Alimoghaddam K, et al: Azidothymidine hinders arsenic trioxide-induced apoptosis in acute promyelocytic leukemia cells by induction of p21 and attenuation of G2/M arrest. Ann Hematol 92: 1207-1220, 2013.

24. Abbas T and Dutta A: p21 in cancer: Intricate networks and multiple activities. Nat Rev Cancer 9: 400-414, 2009.

25. Wang H, Mannava S, Grachtchouk V, Zhuang D, Soengas MS, Gudkov AV, Prochownik EV and Nikiforov MA: c-Myc depletion inhibits proliferation of human tumor cells at various stages of the cell cycle. Oncogene 27: 1905-1915, 2008.

26. Chen D, Huang J, Zhang K, Pan B, Chen J, De W, Wang R and Chen L: MicroRNA-451 induces epithelial-mesenchymal transition in docetaxel-resistant lung adenocarcinoma cells by targeting proto-oncogene c-Myc. Eur J Cancer 50: 3050-3067, 2014.

27. Shi JW, Liu W, Zhang TT, Wang SC, Lin XL, Li J, Jia JS, Sheng HF, Yao ZF, Zhao WT, et al: The enforced expression of c-Myc in pig fibroblasts triggers mesenchymal-epithelial transition (MET) via F-actin reorganization and RhoA/Rock pathway inactivation. Cell Cycle 12: 1119-1127, 2013.

28. Bhushan B and Kush L: Pharmocophoric studies of anti-telomerase drugs. Int J Innov Res Dev 3: 268-272, 2014. 